\title{
PRÁTICA INTERDISCIPLINAR: ANÁLISE DE UM RELATO DE EXPERIÊNCIA DO ENSINO MÉDIO INOVADOR EM TEMPO INTEGRAL
}

\author{
INTERDISCIPLINARY PRACTICE: ANALYSIS OF AN EXPERIENCE REPORT \\ FROM AN INNOVATIVE FULL-TIME HIGH SCHOOL PROGRAM
}

\author{
Antonio Paulo Valim Vega ${ }^{1}$, Bruno Cesar Ribeiro ${ }^{2}$, \\ Léo Cezar Padova ${ }^{3}$ e Taís Steffenello Ghisleni ${ }^{4}$
}

\section{RESUMO}

Esse ensaio tem por objetivo geral analisar como a interdisciplinaridade surge a partir de um relato em torno de uma prática desenvolvida pelo programa de ensino médio inovador em tempo integral, no contexto de escola público estadual no estado de Santa Catarina. Para isso, o trabalho utiliza a abordagem qualitativa do tipo exploratória, e o método descritivo é apresentado como um relato de experiência. Através da análise do relato do professor sobre o programa de ensino médio inovador em tempo integral nas escolas públicas no estado Santa Catarina, fica evidente a prática interdisciplinar.

Palavras-chave: Ensino, Interdisciplinaridade, Práticas pedagógicas.

\section{ABSTRACT}

This essay aims to analyze how interdisciplinarity arises from a report around a practice developed by the innovative full-time high school program in the context of a state public school in the state of Santa Catarina. For this, the work uses the qualitative exploratory approach, and the descriptive method is presented as an experience report. Through the analysis of the teacher's report on the innovative full-time high school program in public schools in the state of Santa Catarina, interdisciplinary practice is evident.

Keywords: Teaching, Interdisciplinarity, Pedagogical Practices.

\footnotetext{
${ }^{1}$ Pedagogo. Acadêmico do Mestrado em Ensino de Humanidades e Linguagens - MEHL, Universidade Franciscana UFN. E-mail: paulovega1010@gmail.com

${ }^{2}$ Produtor Audiovisual. Acadêmico do Mestrado em Ensino de Humanidades e Linguagens - MEHL, Universidade Franciscana - UFN. Bolsista CAPES. E-mail: brunocribeiro01@gmail.com

${ }^{3}$ Filósofo. Acadêmico do Mestrado em Ensino de Humanidades e Linguagens - MEHL, Universidade Franciscana - UFN. E-mail: leocezarpadova@gmail.com

${ }^{4}$ Doutora. Professora do Curso de Publicidade e Propaganda e do Mestrado em Humanidades e Linguagens da Universidade Franciscana - UFN. E-mail: taisghisleni@yahoo.com.br
} 


\section{INTRODUÇÃO}

Com o passar dos anos, a interdisciplinaridade vem surgindo como uma grande aliada para a potencialização dos processos de ensino, nos mais variados contextos. Esse movimento pode ser visto através dos documentos mais atuais que norteiam o ensino no Brasil, como exemplo disso, a Base nacional comum curricular - BNCC e a Proposta de experiência curricular inovadora do Ensino Médio.

Conforme a BNCC (2018 p. 16) é preciso “decidir sobre formas de organização interdisciplinar dos componentes curriculares e fortalecer a competência pedagógica das equipes escolares para adotar estratégias mais dinâmicas, interativas e colaborativas em relação à gestão do ensino e da aprendizagem". Trata-se de um trabalho de planejamento entre as quatro grandes áreas do conhecimento ${ }^{5}$ para viabilizarem projetos dinâmicos para um melhor ensino e aprendizagem dos estudantes em nível médio em tempo integral ${ }^{6}$.

Segundo Brasil (2009) a Proposta de experiência curricular inovadora do Ensino Médio, tem por objetivo a melhoria da qualidade do Ensino Médio nas escolas públicas, sinalizando para os seguintes impactos e transformações:

- Superação das desigualdades de oportunidades educacionais;

- Universalização do acesso e permanência dos adolescentes de 15 a 17 anos no Ensino Médio;

- Consolidação da identidade desta etapa educacional, considerando a diversidade de sujeitos;

- Oferta de aprendizagem significativa para jovens e adultos, reconhecimento e priorização da interlocução com as culturas juvenis (BRASIL, 2009, p. 3).

Visando melhorar a qualidade no processo de ensino em nível médio, a partir de 2010 o Estado de Santa Catarina desenvolve políticas em prol de ações para implantação e fortalecimento do ensino médio inovador em tempo integral.

O programa de ensino médio inovador em tempo integral em Santa Catarina tem por objetivo promover mudanças, possibilitar um movimento inverso da sala de aula, com práticas e metodologias inovadoras, articuladas com atividades integradoras nos eixos como: trabalho, ciência, tecnologia e cultura, bem como, o acompanhamento pedagógico; iniciação científica e pesquisa; leitura e letramento; línguas estrangeiras; cultura corporal; produção e fruição em artes; comunicação; cultura digital e mídias; e participação estudantil.

A preocupação é com a necessidade de formação e capacitação dos jovens. Onde se insere a qualificação para o trabalho e acesso à cultura, ciência e tecnologias. Essa perspectiva encontra-se contemplada na ampliação do tempo de estudo que passa a ser integral na escola, considerando: um

\footnotetext{
${ }^{5}$ Em consonância com a Lei de Diretrizes e Bases da Educação Nacional - LDB, entendesse como áreas do conhecimento: linguagens e suas tecnologias, matemática e suas tecnologias, ciências da natureza e suas tecnologias e ciências humanas e sociais aplicadas.

${ }^{6}$ Cf. Portaria MEC no 1.145, de 10 de outubro de 2016 e Resolução no 16, de 7 de dezembro de 2017.
} 
planejamento interdisciplinar, formação continuada de professores, orientação pedagógica, nova base curricular, e estratégias de ensino inovador e integral.

A interdisciplinaridade neste estudo surge através do relato de um dos autores que é professor do ensino médio de carácter "integral e inovador" e vivencia o sistema implantado em algumas escolas públicas localizadas no interior de Santa Catarina. O modelo de ensino está articulado entre disciplinas, práticas e conteúdo, contando com uma carga horária aumentada, articulado entre teoria e prática, bem como, uma ampliação e reestruturação do currículo interdisciplinarmente.

O relato que será analisado aqui, fez parte da Serie Interdisciplinaridade no Ensino Médio. Serie essa que contou com a elaboração de diversos vídeo aulas no formato "Drops" (vídeo de curta duração) com o objetivo de conscientizar e auxiliar os professores no trabalho interdisciplinar. O processo de elaboração desses conteúdos está descrito no artigo "Interdisciplinaridade na produção de conteúdos educacionais: a relação teoria e prática" (VEGA; RIBEIRO; PADOVA; GHISLENI, 2020).

Esse ensaio tem por objetivo geral analisar como a interdisciplinaridade surge a partir de um relato em torno de uma prática desenvolvida pelo programa de ensino médio inovador em tempo integral, no contexto de escola público estadual no estado de Santa Catarina. Para isso, o trabalho utiliza a abordagem qualitativa do tipo exploratória, e o método descritivo é apresentado como um relato de experiência.

Esse artigo está estruturado da seguinte forma: inicia com a seção teórica que envolve os conceitos relacionados ao Interdisciplinaridade apresentando o contexto histórico, conceitos e fundamentos; em seguida são apresentados os procedimentos metodológicos e à descrição da vivência do professor no contexto do programa de ensino médio inovador em tempo integral, através de um relato de experiência; e finaliza com as considerações finais e as referências bibliográficas utilizadas no texto.

\section{INTERDISCIPLINARIDADE: UM CONTEXTO HISTÓRICO}

O movimento Interdisciplinar surge na Europa, principalmente França e Itália, influenciado pela crise estudantil universitária que na década de 1960, pedia a superação da dicotomia mundo/presente, mundo/pessoal no ensino universitário que não contemplava uma relação e nem visão crítica que levasse em conta as dificuldades e impasses da realidade cotidiana.

Consta também, que os primeiros registros que se tem notícia da interdisciplinaridade dizem que Georges Gusdorf apresentou à Organização das Nações Unidas para a Educação, a Ciência e a Cultura - UNESCO em 1961 um projeto de pesquisa interdisciplinar para as ciências humanas. De acordo com Fazenda (2003), a ideia central deste projeto seria reunir um grupo de cientistas de notório saber para a realização de uma pesquisa interdisciplinar nas ciências humanas no sentido de orientar as ciências para atuar na convergência, para trabalhar pela unidade humana. Assim, encontrar formas de superar a fragmentação do saber. 
O projeto de Gusdorf previa a aproximação teórica entre as ciências humanas, a ideia foi retomada em outras diretrizes e patrocinada pela UNESCO e o projeto foi publicado em 1968, nesse projeto fizeram parte estudiosos das principais universidades europeias e americanas. A pretensão seria a construção das ciências do amanhã no dizer de Levy Strauss e a construção das ciências em movimento no dizer de Jean Piaget (FAZENDA, 2003, p. 20).

Paralelo a proposta da Unesco em Louvain na Bélgica em 1967, realizou-se um colóquio para refletir sobre o estatuto epistemológico da teologia, um exercício que acabou por indicar caminhos para a discussão sobre a interdisciplinaridade. O problema discutido no colóquio girava em torno da necessidade de estudar e pesquisar as relações igreja e mundo. E isso, acabou por promover o encontro dos futuros teóricos da interdisciplinaridade, que se dispuseram a definir o sentido da reflexão, os métodos convenientes e os meios necessários à execução do referido projeto.

Um fato curioso na história da interdisciplinaridade é que seus primeiros entendimentos partem em meio a um diálogo ecumênico que tentava identificar as dificuldades decorrentes da comunicação, do quão difícil seria poder dizer e se fazer compreender pelos outros. Muitas das discussões de meados do século XX em Louvain como o papel do tempo, do espaço, valor e campo da ciência, as relações afetivas entre os participantes e colaboradores de um projeto, foram preocupações que acabaram por constituir o centro das discussões que envolvem a interdisciplinaridade até os dias atuais.

Na revisão histórica apresentada em Fazenda (2003), consta que foi nesse trabalho que os cientistas desvendaram uma hipótese teórica a mais para aprender e investigar, o estudo da dicotomia ser/existir e a discussão interdisciplinar sujeito humano/mundo que ainda hoje nos conduz na busca por respostas.

Em 1971 a Organização de Cooperação e de Desenvolvimento Econômico - OCDE patrocinou um grupo de experts para redigir um documento elucidativo dos principais problemas do ensino e da pesquisa nas universidades. Essa proposta levou a uma nova concepção de universidade onde as disciplinas poderiam inovar em atividades e pesquisas coletivas, buscar diálogo, aproximações e revisão das relações disciplinares, isto é, buscar a atitude interdisciplinar.

No Brasil a primeira produção de impacto significativo sobre o tema pertence a Hilton Japiassú com a publicação de Interdisciplinaridade e patologia do saber, 1976. Um estudo que representa a terceira parte de sua tese de doutoramento que se deu na França. Contempla as principais questões que envolvem a interdisciplinaridade e apresenta os pressupostos para uma metodologia interdisciplinar.

Assim, com as referências de Japiassú (1976), pode-se dizer que a interdisciplinaridade surge para se contrapor e refutar toda e qualquer proposta de ensino e conhecimento que seja limitadora e fragmentadora do sentido e entendimento do mundo e da vida.

Os estudos de Japiassú (1976) sobre interdisciplinaridade, alertam para a limitação da educação disciplinar. Decorre daí sua visão da interdisciplinaridade como uma patologia, somente curada após a tomada de consciência e despertar do saber, curar a patologia, nesse sentido, é estar aberto para o conhecimento. 
A ciência é a consciência do mundo. A doença do mundo corresponde a um fracasso, a uma demissão do saber. [...]. Nesse sentido, podemos falar de uma alienação do humano, prisioneiro de um discurso tanto mais rigoroso quanto mais bem separado da realidade global, pronunciando-se num esplêndido isolamento relativamente à ordem das realidades humanas (GUSDORF, 1976, p. 14).

O autor acredita ser a ciência a consciência do mundo, da mesma forma acredita, que esse mesmo mundo padece de um mal doentio e insano, e facilmente se pode transferir essa crença para os dias atuais, pois, as crises se acumulam nas mais diversas áreas: as exigências, opressões, competições, privações, inseguranças, injustiças, desigualdade e pobreza, ainda persistem, mas igualmente vivemos em um mundo de opulência, com mudanças extraordinárias nas ciências da saúde, tecnologias e outras, avançam os conceitos de direitos humanos e liberdades.

É necessário situar o homem neste espaço dual, sendo preciso organizar os saberes de forma que se possa usufruir e potencializar as fortalezas das pessoas e usar a ciência com sabedoria, pensar e agir interdisciplinarmente pode ser a chave para acessar uma vida com mais satisfação e realização, ao menos, que entenda melhor a realidade que se vive.

\section{CONCEITOS E FUNDAMENTOS}

O conceito de interdisciplinaridade envolve certo grau de complexidade, pois a palavra é um neologismo, evoca uma série de possibilidades e cuja definição nem sempre recebe a mesma interpretação. Mas, mesmo diante de várias terminologias e interpretações o princípio delas é sempre o mesmo: "A interdisciplinaridade se caracteriza pela intensidade das trocas entre os especialistas e pelo grau de integração real das disciplinas no interior de um mesmo projeto de pesquisa.” (JAPIASSÚ, 1976, p. 74).

Construir uma identidade pessoal e coletiva num espaço de trabalho com base em conceito e fundamento interdisciplinar requer a superação de algumas barreiras e limitações. Para Fazenda (2002), as barreiras de diferentes ordens se apresentam, mas, a mais séria das limitações é a de natureza pessoal. Por isso, uma das características da atitude interdisciplinar é a aceitação pelo pensamento e prática do outro. Construir essa atitude exige um entendimento e atuação na perspectiva da intersubjetividade.

No que se refere à construção de uma identidade pessoal para atuar interdisciplinarmente, torna-se importante reconhecer que isso exige uma tomada de consciência, pois, o desenvolvimento de capacidades, o senso de compromisso com os alunos, são aspectos que caracterizam a trajetória do profissional. Competência, envolvimento e compromisso marcam o itinerário desse profissional que luta por uma educação melhor, afirmando-a diariamente. (FAZENDA, 2003, p. 49).

Mas, um bom profissional, também, precisa de espaço, estrutura adequada, apoio e acolhimento institucional de suas iniciativas. Por isso, uma instituição que deseje implantar uma proposta interdisciplinar, necessita de capacitação das pessoas e alterações na sua dinâmica de funcionamento. 
Assim, em Fazenda (2003, p. 50) encontra-se alguns requisitos a considerar na implantação de um projeto de capacitação docente no sentido de instrumentalizar a interdisciplinaridade no ensino, quais sejam:

\footnotetext{
- buscar o engajamento do professor, independentemente de sua visão fragmentada;

- capacitar o professor para compreender como ocorre o processo de aprendizagem, o seu e dos alunos;

- promover e estimular espaços e tempos para exercício do diálogo entre os professores;

- encontrar formas de efetuar a transformação social (coletiva) no mesmo tempo que ocorre o processo de transformação pessoal (individual);

- promover a troca e compartilhamento de experiências.
}

Um outro ponto importante a situar como fundamento da interdisciplinaridade e para Fazenda (2003), surge como uma condição de sobrevivência do conhecimento educacional é a parceria, pois o professor precisa sempre de apoio, de troca da experiência vivida com o outro. A parceria com outros educadores, com os teóricos, com os alunos é o que irá fortalecer e ajudar na construção de um conhecimento mais elaborado.

No que se refere às contribuições da interdisciplinaridade para a ciência e o ensino, Heloisa Luck (2004), esclarece que no campo da ciência a interdisciplinaridade se insere para resolver duas ordens de dificuldades, uma em relação ao conhecimento produzido e a outra em relação à produção de novos conhecimentos.

Dessa forma na primeira ela tem a função de entender e identificar os pontos convergentes e de religação dos saberes já produzidos, na segunda a interdisciplinaridade tem a função de produzir novos conhecimentos nessa concepção, isto é, um conhecimento que indica sua construção ter ocorrido no centro do movimento interdisciplinar.

No entanto, o lado prático da interdisciplinaridade precisa de planejamento sistemático, tendo em vista os frequentes fracassos decorrentes de ações não programadas adequadamente, há que se fazer as distinções entre as estratégias válidas para o ensino e aquelas que são pertinentes à pesquisa. Para Paviani (2008), refletir sobre essas experiências pode ser um modo de esclarecer e de aprofundar o conceito de ação interdisciplinar.

\section{MÉTODOS E TÉCNICAS}

Essa pesquisa conta com uma abordagem qualitativa do tipo exploratória e descritiva. Segundo Minayo (2007) a pesquisa qualitativa permite que o pesquisador possa realizar uma análise aprofundada do objeto de estudos, sem se preocupar em lidar com números ou quantificação de resultados.

Em um primeiro momento foi realizada uma pesquisa exploratória, com o intuito de aprofundamento teórico sobre a temática Interdisciplinaridade, através dos seguintes autores: Fazenda (2003); Gusdorf (1976); Japiassu (1976); e Luck (2004). Para Michel (2015, p. 48) a pesquisa exploratória é a 
“fase inicial da pesquisa; busca o levantamento bibliográfico sobre o tema, com o propósito de identificar informações e subsídios para definição dos objetivos, determinação do problema e definição dos tópicos do referencial teórico".

Em seguida, foi realizado um relato de experiência com o uso do método descritivo (MICHEL, 2015), em que foram descritas como se dá a organização estrutural para o ensino médio inovador em tempo integral. Essa descrição finalizou com a análise sobre as práticas descritas com enfoque na inserção da interdisciplinaridade neste processo.

\section{RELATO DE EXPERIÊNCIA}

Quadro 1 - Descrição do relato de experiência do Professor.

Para a organização dos conteúdos nas disciplinas que compõem o currículo do ensino
médio de caráter integral e inovador, há uma variedade de possibilidades relacionais entre
as disciplinas de acordo com a necessidade da escola e a disponibilidade de encontro dos
professores, conforme os projetos se articulam. É onde entra o planejamento como uma ação
de extrema importância para o sucesso do programa, por isso, há um complemento na carga
horária do professor como estímulo e compromisso com o planejamento.
A equipe multidisciplinar é composta por todas as áreas do conhecimento realiza um
planejamento coletivo interdisciplinar, um trabalho integrado com todos os profissionais da
unidade escolar, sob coordenação do assistente técnico pedagógico, ou da direção. Com de-
senvolvimento de reuniões, atividades de aprendizagem, projetos pedagógicos, organização
de relatórios e registros em ata.
Para atender o programa a escola compõe a equipe com um orientador de leitura; um
orientador de convivência; um orientador do laboratório de química; um orientador para o
laboratório de física; um orientador para o laboratório de biologia, um orientador para labo-
ratório de matemática e um orientador para o laboratório de informática, todos trabalhando
no horário escolar.
Para tudo isso dar certo é necessário muito empenho e vontade da equipe docente, família,
comunidade e estudantes que passam dois dias em periodo integral na escola, politicas públi-
cas para atender aos programas do Ensino Médio integral em Tempo Integral e de carácter
inovador. Esse é um relato de experiência que vem sendo testada em algumas escolas de Santa
Catarina, e traz bons resultados.

Fonte: Elaboração como base no relato do professor/autor (2019)

\section{DISCUSSÃO E RESULTADOS}

Percebe-se no relato de um professor que o ensino médio inovador em tempo integral, uma política pública instituída em algumas escolas estaduais de Santa Catarina estão se constituindo em fortes bases interdisciplinares.

No relato do professor encontram-se referências indicativas de uma fundamentação interdisciplinar, pois, uma das questões anunciadas pelo professor traz o planejamento como uma ação importante para impulsionar que ocorra o diálogo entre a equipe. 
Apenas definir e idealizar um projeto, ou mesmo, este se encontrar delineado numa política pública não garante a concretização da proposta. A interdisciplinaridade é um movimento circular e ininterrupto que precisa ser alimentado constantemente. $\mathbf{O}$ planejamento, as reuniões sistemáticas, as atividades de aprendizagens, a elaboração de projetos, a organização de relatórios, os registros de atividades e tarefas, todas estas questões colaboram para que ocorra um diálogo intersubjetivo, tão afinado com a interdisciplinaridade.

A isso, Fazenda (2003) denomina de fundamentos para a sobrevivência do conhecimento educacional, ou seja, o fortalecimento das relações, a formação de parcerias e o compartilhamento de experiências facilitam e ajudam na construção de novos conhecimentos.

O planejamento amparado nas características evidenciadas no relato do professor denota um grau de maturidade em relação a compreensão, intencionalidade e compromisso da equipe com o projeto do ensino médio inovador em tempo integral numa base interdisciplinar.

Dessa forma, outras fontes do relato nos indicam que o ensino médio inovador em tempo integral está trilhando os caminhos da interdisciplinaridade. Pois, esse caminho nunca é linear, estanque e fechado. A interdisciplinaridade é um percurso aberto, em construção e diálogo permanente. Um recorte do relato diz: a organização dos conteúdos que compõem o currículo nas disciplinas indica que há várias possibilidades, fica claro que essa assertiva encontra referência nos fundamentos interdisciplinares.

Para Luck (2004) é necessário reconhecer que as disciplinas são parte do desenvolvimento histórico, mas, na realidade atual, não conseguem mais dar conta separadamente do conhecimento pertinente. $\mathrm{O}$ mundo é composto de uma multiplicidade de fatores que não são excludentes e não consiste de coisas isoladas. Por isso, é necessário entender a tendência à complexidade e que o mundo se encontra em transição e mudanças contínuas, e em decorrência disso, emerge uma visão da realidade que transcende a disciplina. A visão interdisciplinar reconhece essas características da disciplina e busca a superação dessa limitação, não somente pela integração de conhecimento produzidos nos vários campos de saberes. Mas por uma visão que busca o sentido de unidade na produção de conhecimento novo.

Encontra-se também no relato a questão do reconhecimento e valorização do profissional pelo seu empenho e compromisso, assim como, o estímulo para prosseguir na caminhada. Diz o professor em seu relato: há um complemento na carga horária do professor como estímulo e compromisso com o planejamento.

O reconhecimento pelo empenho e compromisso do profissional vem na forma pagamento pelas horas dedicadas no planejamento, isso serve de estímulo e valorização do trabalho e do tempo que o profissional dedica para obter um desempenho melhor na sua atividade, para desenvolver competências e ofertar resultados de qualidade no exercício profissional. 
Fazenda (2003), esclarece que um projeto de capacitação docente deve ser capaz de promover e estimular espaços e tempos para exercício do diálogo entre os professores, assim como, deve buscar o engajamento do professor, independentemente de sua visão fragmentada.

Percebe-se que a questão de valorização e reconhecimento é uma forma de buscar o engajamento do profissional, de fortalecer e construir novas competências profissionais, de promover estímulo e desejo de capacitação e desenvolvimento de atitudes novas e coerentes com uma proposta inovadora e interdisciplinar.

Pois, uma instituição que deseja implantar uma proposta interdisciplinar precisa investir seriamente no processo de capacitação de todos os envolvidos. Assim, promover a integração de todos os profissionais da escola, comunidade, docentes, estudantes, família, torna-se um desafio inerente a um projeto interdisciplinar.

O relato de experiência do professor, apresenta a forma como está acontecendo o ensino inovador em tempo integral em algumas escolas de Santa Catarina. Anuncia que as práticas estão se efetivando e se dando em plena coerência com as referências teóricas e estudos da interdisciplinaridade.

\section{CONSIDERAÇÕES FINAIS}

Através da análise do relato do professor sobre o programa de ensino médio inovador em tempo integral nas escolas públicas no estado Santa Catarina, fica evidente a prática interdisciplinar, principalmente durante os planejamentos onde todos integrantes da escola participam, podendo assim propor atividade conjuntas.

Outro fator fundamental é estímulo financeiro aos profissionais aumentando a carga horária dos professores que se comprometem com o projeto. Isso acaba por gerar um compromisso maior com o planejamento, e um engajamento também por parte dos profissionais para com o programa de ensino médio inovador em tempo integral.

Para trabalhar interdisciplinarmente, os compartilhamentos, as trocas e formas de aprendizagem contribuem: as reuniões sistemáticas, às atividades de aprendizagens, a elaboração de projetos, a organização de relatórios, os registros de atividades e tarefas. Todas essas práticas ajudam para que professores e alunos entendam que a interdisciplinaridade é um processo dialógico de construção permanente e depende de todos os envolvidos para funcionar.

Concluindo esta reflexão, é importante lembrar que a intencionalidade das ações e o diálogo aberto e construtivo, são elementos de fundamental importância na realização e implantação de projetos numa concepção interdisciplinar. 


\section{REFERÊNCIAS}

BRASIL, Ministério da Educação. Base Nacional Comum Curricular, 2018.

BRASIL, Ministério da Educação. Proposta de experiência curricular inovadora do Ensino Médio. Parecer n ${ }^{0}$ 11, 2009.

FAZENDA, Ivani. Interdisciplinaridade: história, teoria e pesquisa. Papirus, 11. ed. Campinas, SP, 2003.

FAZENDA, Ivani. Interdisciplinaridade: um projeto em parceria. Edições LOYOLA, São Paulo, 2002.

FAZENDA, Ivani. (Coord.). Práticas interdisciplinares na escola. São Paulo: Cortez, 2013.

GUSDORF, Georges. Prefácio. In: JAPIASSU, Hilton. Interdisciplinaridade e patologia do saber. IMAGO, ed. LTDA. RJ, 1976.

LUCK, Heloisa. Pedagogia Interdisciplinar: Fundamentos teórico-metodológico. 12. ed. Petrópolis, RJ, Ed. Vozes, 2004.

JAPIASSÚ, Hilton. Interdisciplinaridade e patologia do saber. IMAGO, ed. LTDA. RJ, 1976.

MINAYO, Maria Cecília de Souza. O desafio do conhecimento: pesquisa qualitativa em saúde. 10. ed. São Paulo: Hucitec, 2007.

MICHEL, Maria Helena. Metodologia e pesquisa científica em ciências sociais: um guia prático para acompanhamento da disciplina e elaboração de trabalhos monográficos. 3. ed. São Paulo: Atlas, 2015

PAVIANI, Jayme. Interdisciplinaridade: conceitos e distinções. Caxias do Sul, RS: Educs, 2008.

VEGA, Antonio Paulo Valim; RIBEIRO, Bruno Cesar; PADOVA, Léo Cezar; GHISLENI, Taís Steffenello. Interdisciplinaridade na produção de conteúdos educacionais: a relação teoria e prática. Research, Society and Development, v. 9, n.1, e128911791, 2020. Disponível em: https:// bit.ly/2GhHxhn. Acesso em: 14/01/2020. 